\title{
Effect of Antrodia camphorata on Inflammatory Arterial Thrombosis-Mediated Platelet Activation: The Pivotal Role of Protein Kinase C
}

\author{
Wan-Jung Lu, ${ }^{1,2}$ Shih-Chang Lin, ${ }^{1,3,4,5}$ Chang-Chou Lan, ${ }^{6}$ Tzu-Yin Lee, ${ }^{1}$ Chih-Hsuan Hsia, ${ }^{1}$ \\ Yung-Kai Huang, ${ }^{7}$ Hsiu-Chuan Lee, ${ }^{2,8}$ and Joen-Rong Sheu ${ }^{1}$ \\ ${ }^{1}$ Graduate Institute of Medical Sciences and Department of Pharmacology, College of Medicine, Taipei Medical University, \\ 250 Wu-Hsing St., Taipei 11031, Taiwan \\ ${ }^{2}$ School of Nutrition and Health Sciences, Taipei Medical University, Taipei 11031, Taiwan \\ ${ }^{3}$ Division of Allergy and Immunology, Department of Internal Medicine, Cathay General Hospital, Taipei 10630, Taiwan \\ ${ }^{4}$ The Laboratory of Allergy and Immunology, Cathay Medical Research Institute, New Taipei City 22171, Taiwan \\ ${ }^{5}$ Department of Medicine, School of Medicine, Fu Jen Catholic University, New Taipei City 24205, Taiwan \\ ${ }^{6}$ Sheen Chain Biotechnology, Co. Ltd., Taipei 11503, Taiwan \\ ${ }^{7}$ School of Oral Hygiene, College of Oral Medicine, Taipei Medical University, Taipei 11031, Taiwan \\ ${ }^{8}$ Program for Translation Medicine, Taipei Medical University, 250 Wu-Hsing St., Taipei 11031, Taiwan
}

Correspondence should be addressed to Hsiu-Chuan Lee; hcjoyce.lee@gmail.com and Joen-Rong Sheu; sheujr@tmu.edu.tw

Received 5 August 2014; Accepted 11 September 2014; Published 14 October 2014

Academic Editor: Duen-Suey Chou

Copyright (C) 2014 Wan-Jung Lu et al. This is an open access article distributed under the Creative Commons Attribution License, which permits unrestricted use, distribution, and reproduction in any medium, provided the original work is properly cited.

\begin{abstract}
Antrodia camphorata is a rare Taiwanese medicinal mushroom. Antrodia camphorata extract has been reported to exhibit antioxidant, anti-inflammation, antimetastasis, and anticancer activities and plays a role in liver fibrosis, vasorelaxation, and immunomodulation. Critical vascular inflammation leads to vascular dysfunction and cardiovascular diseases, including abdominal aortic aneurysms, hypertension, and atherosclerosis. Platelet activation plays a crucial role in intravascular thrombosis, which is involved in a wide variety of cardiovascular diseases. However, the effect of Antrodia camphorata on platelet activation remains unclear. We examined the effects of Antrodia camphorata on platelet activation. In the present study, Antrodia camphorata treatment $(56-224 \mu \mathrm{g} / \mathrm{mL})$ inhibited platelet aggregation induced by collagen, but not U46619, an analogue of thromboxane $\mathrm{A}_{2}$, thrombin, and arachidonic acid. Antrodia camphorata inhibited collagen-induced calcium $\left(\mathrm{Ca}^{2+}\right)$ mobilization and phosphorylation of protein kinase C (PKC) and Akt. In addition, Antrodia camphorata significantly reduced the aggregation and phosphorylation of $\mathrm{PKC}$ in phorbol-12, 13-dibutyrate (PDBu) activated platelets. In conclusion, Antrodia camphorata may inhibit platelet activation by inhibiting of $\mathrm{Ca}^{2+}$ and PKC cascade and the Akt pathway. Our study suggests that Antrodia camphorata may be a potential therapeutic agent for preventing or treating thromboembolic disorders.
\end{abstract}

\section{Introduction}

Antrodia camphorata is a rare Taiwanese medicinal mushroom that is popularly known as "niu cheng zhi" in Taiwan [1]. Antrodia camphorata has been used in traditional Chinese medicine to treat food poisoning, drug intoxication, diarrhea, abdominal pain, hypertension, skin irritation, and cancer [2]. Studies have identified bioactive compounds of Antrodia camphorata, including polysaccharides, maleic/succinic acid derivatives, triterpenoids, benzenoids, and benzoquinone derivatives $[3,4]$. In addition, Antrodia camphorata was reported to induce apoptosis in SKOV-3 cells through ROS generation, loss of HER-2/neu activation, and suppression of its downstream signaling pathways, including the PI3K/Akt cascade [5]. In addition, Antrodia camphorata inhibited lipopolysaccharide- (LPS-) 
induced NO production in macrophages [6]. Recent studies have reported that Antrodia camphorata is involved in various biological activities, including antioxidant, antiinflammation, antimetastasis, and anticancer activities as well as liver fibrosis, vasorelaxation, and immunomodulation [79].

Critical vascular inflammation leads to vascular dysfunction and cardiovascular diseases, including abdominal aortic aneurysms, hypertension, and atherosclerosis. Intravascular thrombosis is involved in a wide variety of cardiovascular diseases (CVDs). Intraluminal thrombosis is believed to be initiated by platelet adherence and aggregation. Thus, in addition to mediating hemostasis, platelet aggregation may play a crucial role in atherothrombotic processes [10].

Blood platelet activation and aggregation constitute a common denominator in atherothrombotic events and various inflammatory diseases. Platelets have been viewed exclusively as mediators of thrombosis and hemostasis, but a study recently indicated that they play key roles in inflammation and immunity [11]. Therefore, the use of antiplatelet agents to treat thromboembolic diseases (myocardial infarction, ischaemic stroke, and vascular death) warrants investigation. During a preliminary study, we observed that Antrodia camphorate at $224 \mu \mathrm{g} / \mathrm{mL}$ inhibited the collagen-induced aggregation of washed human platelets. The influence of Antrodia camphorata on platelet activation has yet to be investigated thoroughly. We systematically examined the effects of Antrodia camphorata on human platelets and characterized the detailed mechanisms of Antrodia camphorata-mediated inhibition of platelet activation.

\section{Materials and Methods}

2.1. Plant Material. Crude extracts of Antrodia camphorata (70\%) were provided by Well Shine Biotechnology Development Co., Pvt. Ltd., Taipei, Taiwan.

2.2. Materials. Type I collagen and phorbol-12, 13-dibutyrate $(\mathrm{PDBu})$ were purchased from Sigma (St Louis, MO). Fura 2-AM was purchased from Molecular Probe (Eugene, OR). The anti-Akt (pan) (40D4) monoclonal antibody (mAb), anti-phospho-Akt (Ser ${ }^{473}$ ) polyclonal antibody (pAb), antiphospho-(Ser) protein kinase $\mathrm{C}$ (PKC) substrate pAb, antiphospho-p38 mitogen-activated protein kinase (MAPK) $\left(\mathrm{Thr}^{180} / \mathrm{Tyr}^{182}\right.$ ) pAb, anti-p38 MAPK (5F11) mAb, antiphospho-p44/42 MAPK (ERK1/2) $\left(\mathrm{Thr}^{202} / \mathrm{Tyr}^{204}\right) \mathrm{pAb}$, antip44/42 MAPK (137F5) mAb, anti-phospho-c-Jun N-terminal kinse (JNK) ( Thr $^{183} /$ Tyr $\left.^{185}\right) \mathrm{mAb}$, and anti-JNK pAb were purchased from Cell Signaling (Beverly, MA). The anti- $\alpha$ tubulin mouse $\mathrm{mAb}$ was purchased from Thermo Scientific (Waltham, MA). The Hybond-P polyvinylidene difluoride (PVDF) membrane, an enhanced chemiluminescence (ECL) western blotting detection reagent, a horseradish-peroxidase (HRP)-conjugated donkey anti-rabbit IgG, and a sheep antimouse IgG were purchased from Amersham (Buckinghamshire, UK).
2.3. Platelet Aggregation Assay. Our study was approved by the Institutional Review Board of Taipei Medical University and conformed to the directives of the Helsinki Declaration. All human volunteers provided informed consent. Human platelet suspensions were prepared as described in a previous report [10]. Blood was collected from healthy human volunteers who had taken no medication during the preceding 2 weeks, and the blood samples were mixed with acid-citrate-dextrose solution. After centrifugation at $120 \mathrm{~g}$ for $10 \mathrm{~min}$, the supernatant (platelet-rich plasma; PRP) was supplemented with $\mathrm{PGE}_{1}(0.5 \mu \mathrm{M})$ and heparin $(6.4 \mathrm{IU} / \mathrm{mL})$ and then incubated for $10 \mathrm{~min}$ at $37^{\circ} \mathrm{C}$ and centrifuged at $500 \mathrm{~g}$ for $10 \mathrm{~min}$. The platelet pellets were suspended in $5 \mathrm{~mL}$ of Tyrode's solution, $\mathrm{pH} 7.3$ [containing (mM) NaCl 11.9, $\mathrm{KCl}$ 2.7, $\mathrm{MgCl}_{2}$ 2.1, $\mathrm{NaH}_{2} \mathrm{PO}_{4} 0.4, \mathrm{NaHCO}_{3} 11.9$, and glucose $11.1]$; then apyrase $(1.0 \mathrm{U} / \mathrm{mL}), \mathrm{PGE}_{1}(0.5 \mu \mathrm{M})$, and heparin $(6.4 \mathrm{IU} / \mathrm{mL})$ were added, and the mixture was incubated for $10 \mathrm{~min}$ at $37^{\circ} \mathrm{C}$. After centrifugation of the suspensions at $500 \mathrm{~g}$ for $10 \mathrm{~min}$, the washing procedure was repeated. The washed platelets were suspended in Tyrode's solution containing $3.5 \mathrm{mg} / \mathrm{mL}$ of bovine serum albumin (BSA), and the final $\mathrm{Ca}^{2+}$ concentration in the solvent of the suspensions was adjusted to $1 \mathrm{mM}$.

A Lumi-Aggregometer (Payton Associates, Scarborough, $\mathrm{ON}$, Canada) was used to measure platelet aggregation as described in a previous report [10]. Platelet suspensions $(3.6 \times$ $10^{8}$ cells $/ \mathrm{mL}$ ) were preincubated with Antrodia camphorata at various concentrations or a solvent control (0.5\% DMSO) for $3 \mathrm{~min}$ before agonists were added under a stirring condition. The reaction was allowed to proceed for $6 \mathrm{~min}$, and the extent of aggregation was expressed in light transmission units.

2.4. Measurement of Platelet-Relative $\mathrm{Ca}^{2+}$ Mobilization by Using Fura 2-AM Fluorescence. After centrifugation of the citrated whole blood at $120 \times \mathrm{g}$ for $10 \mathrm{~min}$, the supernatant was incubated with $5 \mu \mathrm{M}$ Fura 2 -AM for $1 \mathrm{~h}$ with constant stirring condition. As described above, human platelets were then prepared. Finally, the external $\mathrm{Ca}^{2+}$ concentration of the platelet suspensions was adjusted to $1 \mathrm{mM}$. The relative $\mathrm{Ca}^{2+}$ mobilization was measured using a CAF 110 fluorescence spectrophotometer (Jasco, Tokyo, Japan) at excitation wavelengths of 340 and $380 \mathrm{~nm}$ and an emission wavelength of $500 \mathrm{~nm}$ as described in a previous report [12].

2.5. Immunoblotting. Washed platelets $\left(1.2 \times 10^{9}\right.$ cells $\left./ \mathrm{mL}\right)$ were preincubated with 112, 224, or $448 \mu \mathrm{g} / \mathrm{mL}$ of Antrodia camphorata or a solvent control for $3 \mathrm{~min}$, and agonists were added to trigger platelet activation under a stirring condition. After the reaction was stopped, platelets were immediately resuspended in $200 \mu \mathrm{L}$ of lysis buffer. Samples containing $80 \mu \mathrm{g}$ of protein were separated on a $12 \%$ acrylamide gel by performing sodium dodecyl sulfate polyacrylamide gel electrophoresis (SDS-PAGE), and the proteins were electrotransferred through semidry transfer (Bio-Rad, Hercules, CA). The blots were blocked with TBST (10 mM Tris-base, $100 \mathrm{mM} \mathrm{NaCl}$, and $0.01 \%$ Tween 20 ) containing 5\% BSA for $1 \mathrm{~h}$ and then probed with various primary antibodies. Membranes were incubated with an HRP-linked anti-mouse 


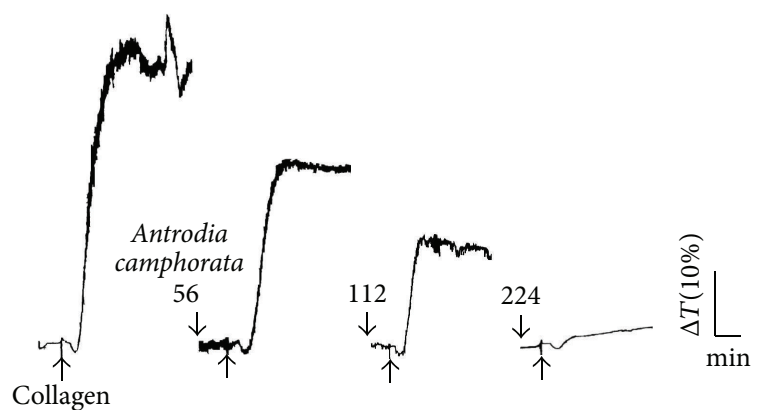

(a)

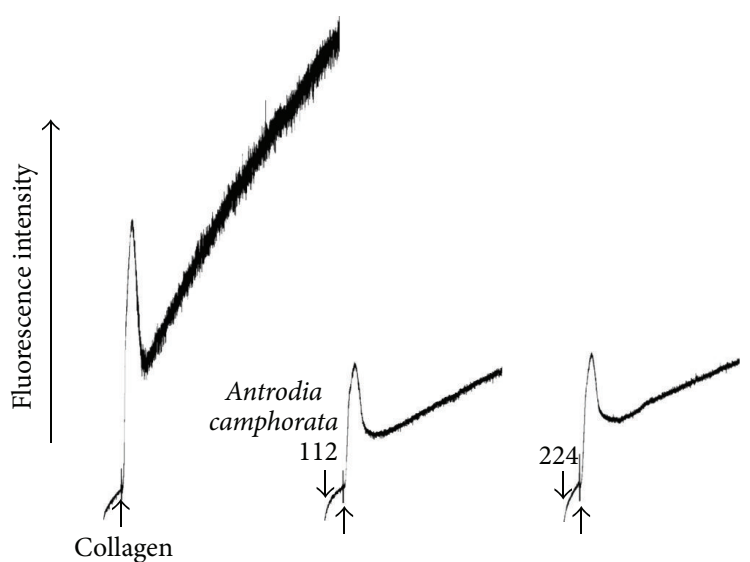

(b)

FIGURE 1: Effects of Antrodia camphorata on the regulation of platelet aggregation and calcium mobilization in washed human platelets. Washed platelets $\left(3.6 \times 10^{8}\right.$ cells $/ \mathrm{mL}$ ) were preincubated with a solvent control (DMSO, $0.05 \%$ ) or 56-224 $\mu \mathrm{g} / \mathrm{mL}$ of Antrodia camphorata, and $1 \mu \mathrm{g} / \mathrm{mL}$ of collagen was subsequently added to trigger (a) platelet aggregation and (b) relative $\mathrm{Ca}^{2+}$ mobilization. Profiles are representative examples of 3 independent experiments.

IgG, anti-goat IgG, or anti-rabbit IgG (diluted 1:3000 in TBST) for $1 \mathrm{~h}$. Immunoreactive bands were detected using an enhanced ECL system. Ratios of the semiquantitative results were obtained by scanning the reactive bands and quantifying the optical density by using a video densitometer and the Biolight, Version V2000.01, computer software (Bioprofil,Vilber Lourmat, France).

2.6. Data Analysis. The experimental results are expressed as the mean \pm SEM and are accompanied by the number of observations $(n)$. Values of $n$ refer to the number of experiments, each of which were conducted using different blood donors. The results of the experiments were evaluated using an analysis of variance (ANOVA). When the ANOVA indicated significant differences among the group means, each group was compared using the Student-Newman-Keuls method. The results of comparisons with a $P$ value less than 0.05 were considered statistically significant. All statistical analyses were performed using the SAS, Version 9.2 software package (SAS Institute, Cary, NC).

\section{Results}

3.1. Effects of Antrodia camphorata on Platelet Aggregation and Intracellular Calcium Mobilization. As shown in Figure 1(a), Antrodia camphorata $(56-224 \mu \mathrm{g} / \mathrm{mL})$ inhibited platelet aggregation following treatment with $1 \mu \mathrm{g} / \mathrm{mL}$ of collagen. In subsequent experiments, $1 \mu \mathrm{g} / \mathrm{mL}$ of collagen was used as an agonist to stimulate platelet aggregation. As shown in Figure 1(b), calcium mobilization in human platelets stimulated with $1 \mu \mathrm{g} / \mathrm{mL}$ of collagen was inhibited by 112 or $224 \mu \mathrm{g} / \mathrm{mL}$ of Antrodia camphorata in a concentrationdependent manner. However, at a concentration of $448 \mu \mathrm{g} / \mathrm{mL}$, Antrodia camphorata did not significantly inhibit platelet aggregation stimulated by $1 \mu \mathrm{M}$ U46619, $0.01 \mathrm{U} / \mathrm{mL}$ of thrombin, or $60 \mu \mathrm{M} \mathrm{AA}$ (data not shown).
3.2. Effects of Antrodia camphorata on Mitogen-Activated Protein Kinases Activation. The MAPKs control major cellular responses in eukaryotic organisms and contribute to cell proliferation, migration, and differentiation as well as apoptosis. Antrodia camphorata did not inhibit collagen-mediated phosphorylation of p38 (Figure 2(a)), ERK (Figure 2(b)), or JNK (Figure 2(c)). These results suggest that Antrodia camphorata does not antagonize collagen-mediated MAPKs intracellular signaling events that occur during platelet activation.

3.3. Effects of Antrodia camphorata on Protein Kinase $C$ Activation. Activation of platelets by various agonists could lead to the induction of PKC activation and subsequent phosphorylation of $\mathrm{p} 47$ proteins [13]. As compared to the protein profile of nonactivated platelets, a protein with an apparent molecular weight similar to that of p47 $(47 \mathrm{kDa})$ was predominately phosphorylated in collagen- (Figure 3(a)) and PDBu- (150 nM; Figures 3(b) and 3(c)) activated human platelets. Antrodia camphorata treatments reduced apparent p47 phosphorylation in both collagen- and PDBu-activated platelets (Figures 3(a) and 3(c)). In addition, $448 \mu \mathrm{g} / \mathrm{mL}$ of Antrodia camphorata significantly reduced the aggregation of $\mathrm{PDBu}$-activated platelets (Figure 3(b)), indicating that Antrodia camphorata directly affects PKC activation in human platelets.

3.4. Effects of Antrodia camphorata on Akt Activation. As shown in Figure 4(a), Antrodia camphorata concentration (112 or $224 \mu \mathrm{g} / \mathrm{mL}$ ) dependently attenuated Akt phosphorylation stimulated by $1 \mu \mathrm{g} / \mathrm{mL}$ of collagen. In addition, Antrodia camphorata did not affect MAPKs phosphorylation in collagen-activated human platelets (Figure 2). These results revealed that Antrodia camphorata may prevent collageninduced platelet activation through the inhibition of PKC and Akt phosphorylation (Figure 4(b)). 


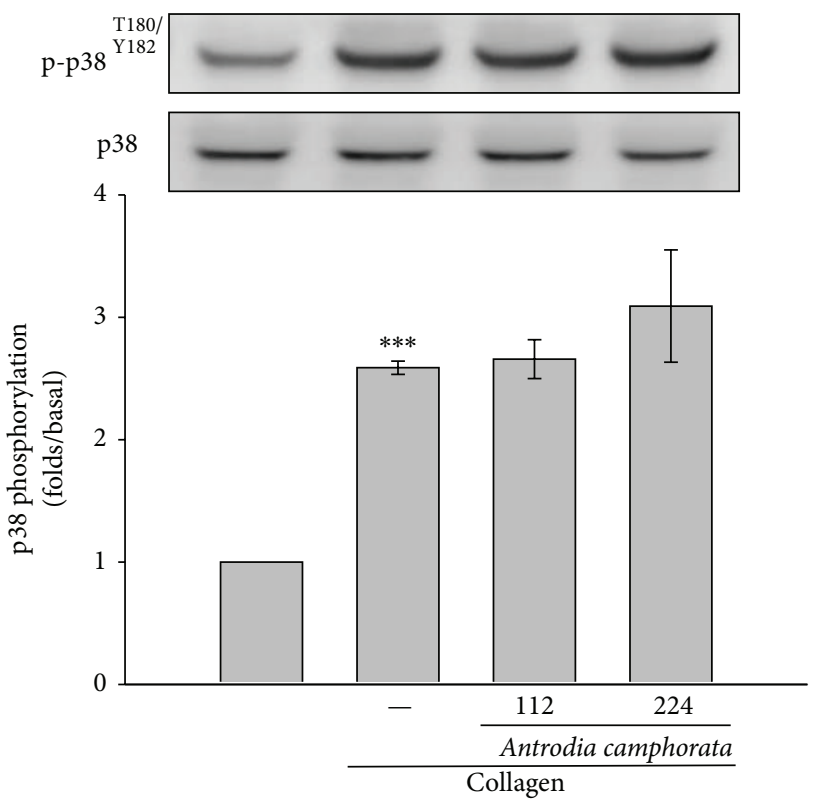

(a)

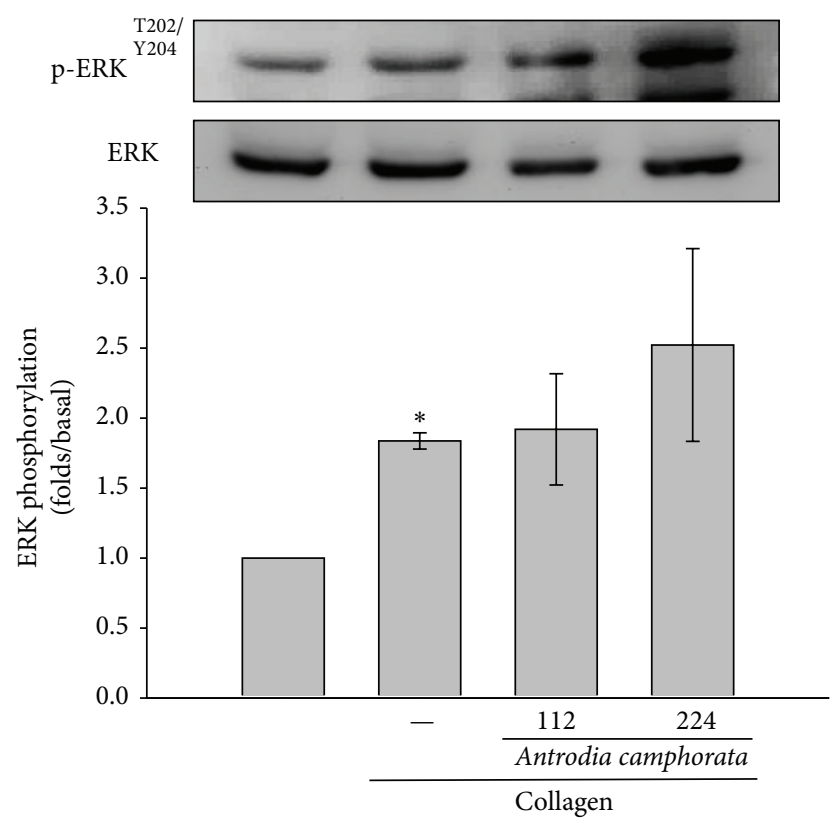

(b)

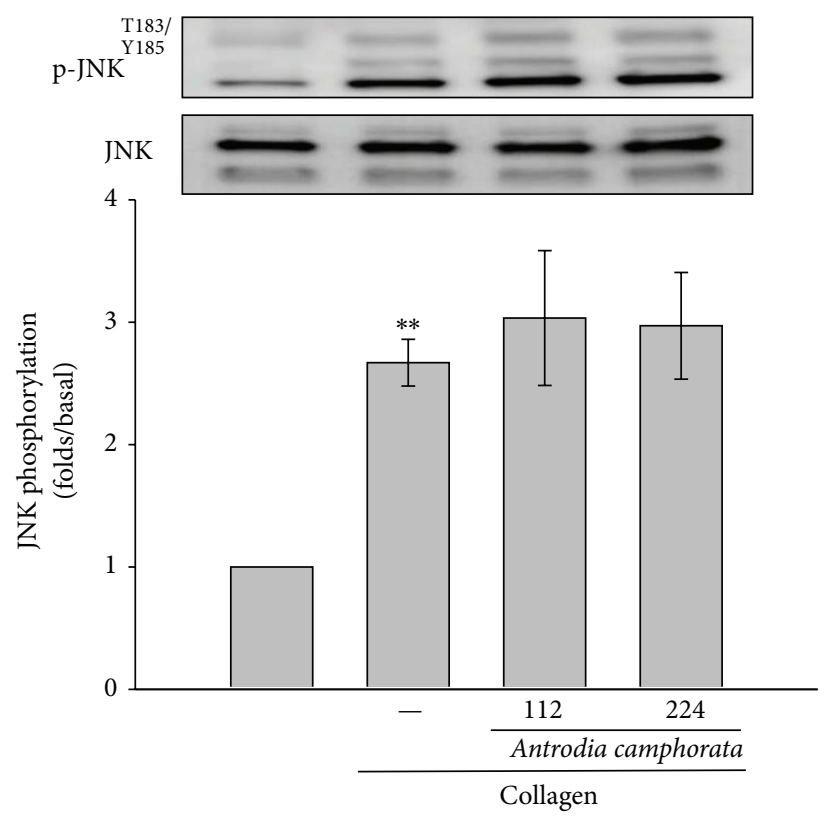

(c)

FIGURE 2: Effects of Antrodia camphorata on MAPK activation in collagen-activated platelets. Washed platelets $\left(1.2 \times 10^{9}\right.$ cells $\left./ \mathrm{mL}\right)$ were preincubated with 112 or $224 \mu \mathrm{g} / \mathrm{mL}$ of Antrodia camphorate and subsequently treated with $1 \mu \mathrm{g} / \mathrm{mL}$ of collagen to induce platelet activation. The platelets were collected, and the phosphorylation of (a) p38, (b) ERK, or (c) JNK in the subcellular extracts was analyzed. Data are presented as the mean $\pm \operatorname{SEM}\left(n=3 ;{ }^{*} P<0.05,{ }^{* *} P<0.01\right.$, and ${ }^{* * *} P<0.001$, compared with solvent control platelets $)$.

\section{Discussion}

This study demonstrated for the first time that Antrodia camphorata exhibits potent antiplatelet activity via inhibiting both PKC and Akt activation in washed human platelets (Figure 4(b)). Antrodia camphorata has been used in traditional Chinese medicine to treat food poisoning, drug intoxication, diarrhea, abdominal pain, hypertension, skin irritation, and cancer [2]. Recent studies have reported that Antrodia camphorata induces substantial apoptosis in human promyelocytic leukemia (HL-60) cells [14]. Another study proved that Antrodia camphorata extracts may be used as an adjuvant antitumor agent for human hepatoma cells, which are resistant to most other antitumor agents. Our previous study demonstrated that Antrodia camphorata provides effective protection against carbon tetrachloride $\left(\mathrm{CCl}_{4}\right)$ 


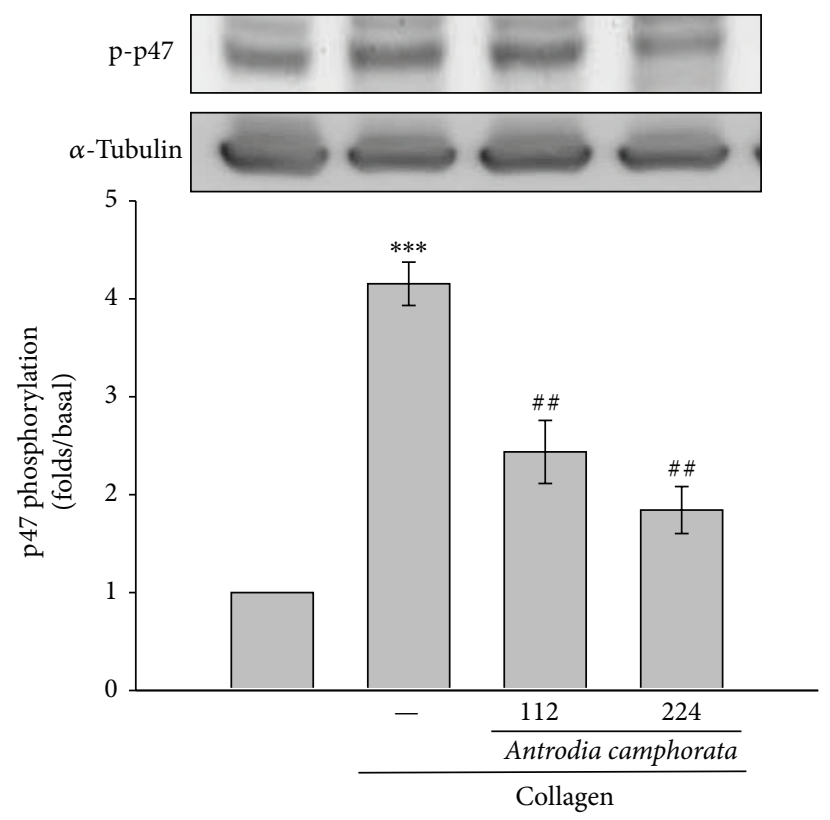

(a)

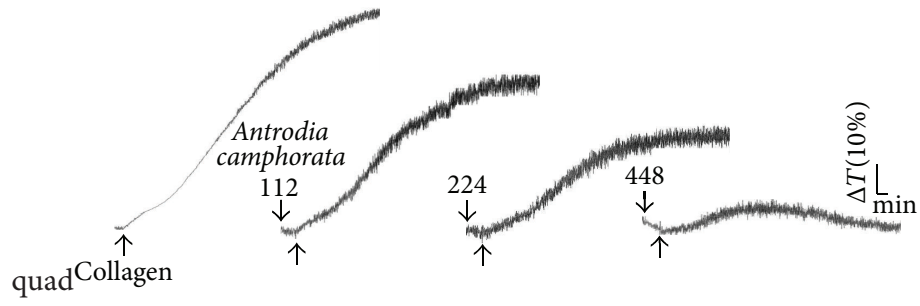

(b)

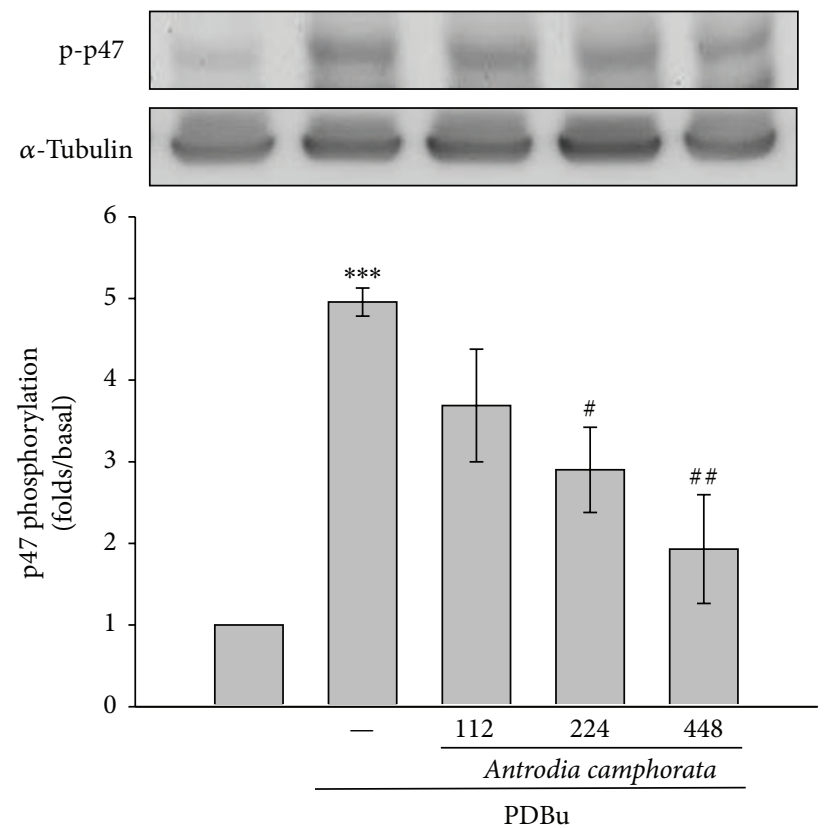

(c)

FIgURE 3: Influence of Antrodia camphorata on PKC activation in activated platelets. ((a) and (c)) Washed platelets were preincubated with 112, 224 , or $448 \mu \mathrm{g} / \mathrm{mL}$ of Antrodia camphorata and subsequently treated with $1 \mu \mathrm{g} / \mathrm{mL}$ of collagen or $150 \mathrm{nM}$ PDBu to induce p47 phosphorylation, the PKC downstream ((a) and (c)), and (b) platelet aggregation. Data are presented as the mean \pm SEM $\left(n=3 ;{ }^{* * *} P<0.001\right.$ compared with solvent control platelets; ${ }^{\#} P<0.01$ and ${ }^{\# \#} P<0.01$ compared with the collagen group). Profiles (b) are representative of 3 independent experiments. 


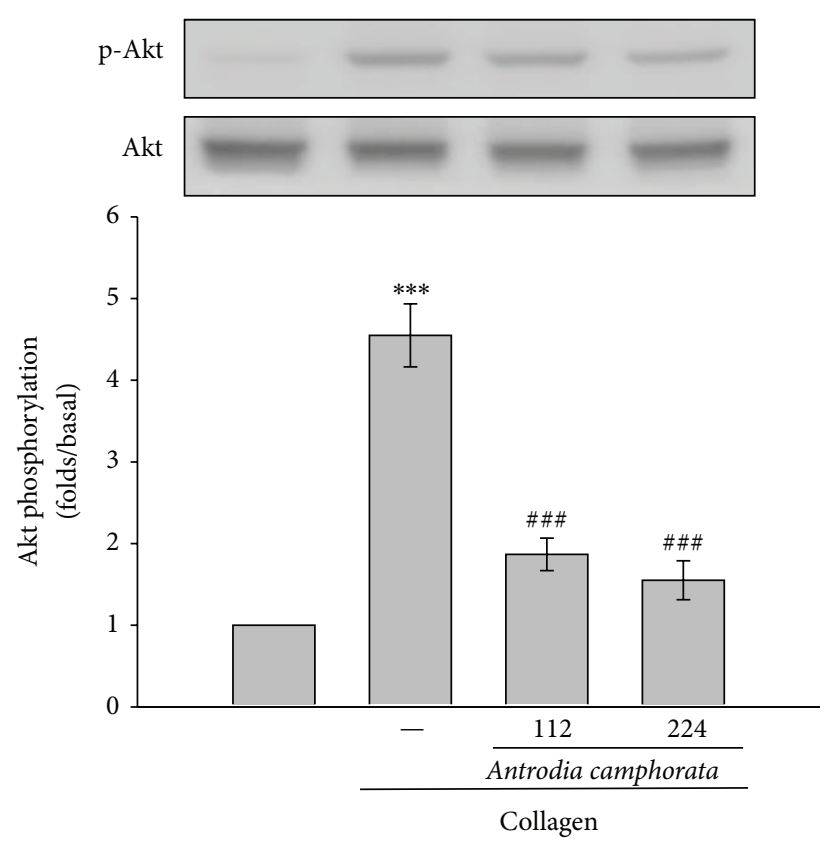

(a)

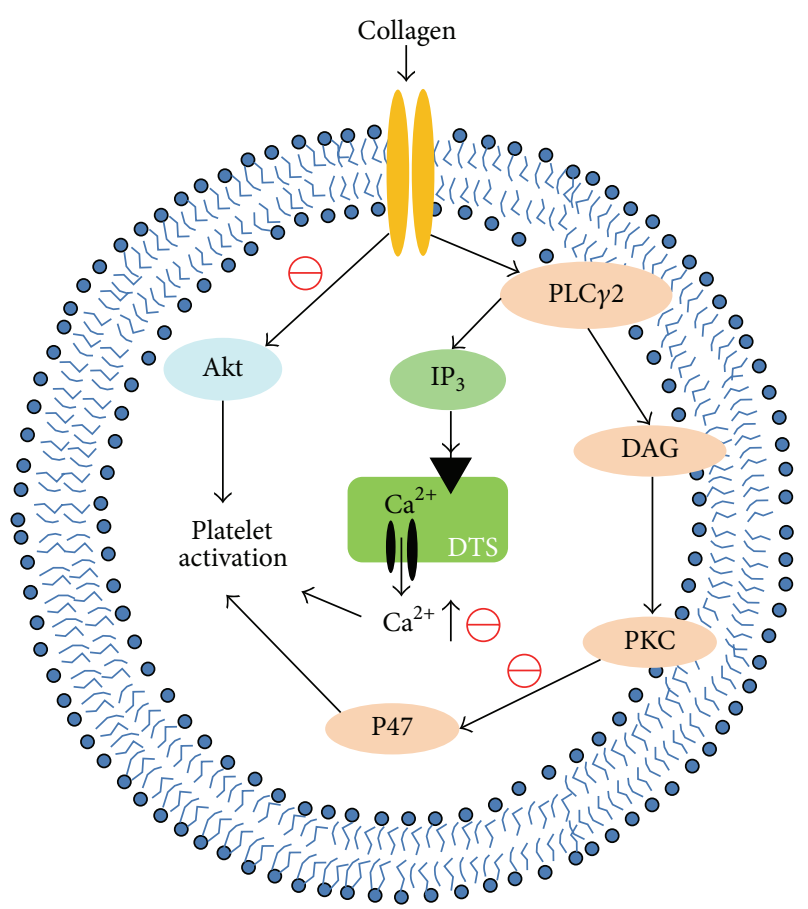

$\ominus$ Antrodia camphorata

(b)

FIGURE 4: Effects of Antrodia camphorata on Akt phosphorylation in collagen-activated platelets. Washed platelets $\left(1.2 \times 10^{9}\right.$ cells $\left./ \mathrm{mL}\right)$ were preincubated with 112 or $224 \mu \mathrm{g} / \mathrm{mL}$ of Antrodia camphorata and subsequently treated with $1 \mu \mathrm{g} / \mathrm{mL}$ of collagen to induce platelet activation. The platelets were collected, and the phosphorylation of (a) Akt in the subcellular extracts was analyzed. Data are presented as the mean \pm SEM $\left(n=3 ;{ }^{* * *} P<0.001\right.$ compared with solvent control platelets; ${ }^{\# \# \#} P<0.001$ compared with the collagen group). (b) Schematic illustration of Antrodia camphorata-mediated inhibition of platelet activation. Activated phospholipase C $\gamma 2$ (PLC $\gamma 2$ ) catalyses the conversion of phosphatidylinositol 4,5-bisphosphate (PI4,5- $\mathrm{P}_{2}$ ) into 1,2-diacylglycerol (DAG) and inositol 1,4,5-trisphosphate (IP ${ }_{3}$ ). DAG activates protein kinase $\mathrm{C}$ (PKC) and, subsequently, phosphorylation of a $47-\mathrm{kD}$ a protein ( $\mathrm{p} 47)$. $\mathrm{IP}_{3}$ induces the release of $\mathrm{Ca}^{2+}$ from the dense tubular system (DTS).

induced hepatic injury in vivo by mediating antioxidative and free radical scavenging activities [15], and it was shown to reduce $\mathrm{H}_{2} \mathrm{O}_{2}$-induced lipid peroxidation and upregulate the expression of hepatic glutathione-dependent enzymes, thereby protecting the rat liver from $\mathrm{CCl}_{4}$-induced damage [16].

Phospholipidase (PL) activation may significantly alter by the occurrence of platelets activation by agonists, such as collagen. Inositol 1,4,5-trisphosphate ( $\left.\mathrm{IP}_{3}\right)$ and 1,2-diacylglycerol (DAG) are produced during the activation of phospholipidase $\mathrm{C}$ (PLC), which activates PKC, and subsequently induce the phosphorylation of $\mathrm{p} 47$ [17]. It has been proposed that activation of PKC may facilitate certain responses to specific activating signals in distinct cellular compartments [18]. The 6 families of PLC enzymes are found to be categorized: PLC $\beta$, PLC $\gamma$, PLC $\delta$, PLC $\varepsilon$, PLC $\zeta$, and PLC $\eta$ [18]. The PLC $\gamma$ family comprises isozymes 1 and 2 and isoform 2 is found to associate in collagen-dependent signaling in platelets [19]. $\mathrm{IP}_{3}$ triggers an increase in intracellular $\mathrm{Ca}^{2+}$ from $\mathrm{Ca}^{2+}$ storage sites (i.e., the dense tubular system, DTS) in platelets. DAG activates PKC-inducing protein phosphorylation (p47) (Figure 4(b)). PKC activation is a strategy adopted by cells to enable certain responses to specific activating signals in distinct cellular compartments [18]. In our study, the activation of both $\mathrm{Ca}^{2+}$ and PKC by collagen was diminished in the presence of Antrodia camphorata. Antrodia camphorata exerted direct effects on PKC activation because it reduced $\mathrm{PDBu}$-induced PKC activation and PDBu-induced platelet aggregation, suggesting that Antrodia camphorata-mediated inhibition of platelet activity involves the $\mathrm{Ca}^{2+}$ and PKC cascade.

MAPKs include ERKs, p38, and JNKs which are involved in cell proliferation, migration, differentiation, and apoptosis. ERKs, JNKs, and p38 have consistently been identified in platelets [20] and they are activated in platelets stimulated by collagen and thrombin and are involved in thrombosis [21]. ERK and p38 play a vital role in stimulating granule secretion and facilitating clot retraction [22]. In addition, p38 plays a crucial role in activating cytosolic phospholipase $\mathrm{A}_{2}$, which produces thromboxane $\mathrm{A}_{2}$ by catalyzing AA release [23]. Moreover, JNK1 is reportedly involved in collageninduced platelet aggregation and thrombus formation [24]. The time of thrombus formation was significantly prolonged in JNK1-/- arterioles in an in vivo model and platelet 
secretion was impaired in JNK1-/- platelets in vitro [25]. Akt is a downstream effector of PI3-kinase [26], and previous studies found that Akt-knockout mice exhibited defects in agonist-induced platelet activation $[27,28]$. In this study, we demonstrated that Antrodia camphorata inhibits the activation of Akt, but not MAPKs, suggesting that the Antrodia camphorata-mediated inhibition of platelet activation may involve inhibition of the Akt cell-signaling pathway.

In conclusion, we demonstrated that the antiplatelet activity of Antrodia camphorata may inhibit the $\mathrm{Ca}^{2+}$ and PKC cascades and Akt signaling pathway (Figure 4(b)). These alterations reduce platelet activity and ultimately inhibit platelet aggregation. Our findings suggest that Antrodia camphorata may be a potential therapeutic agent for preventing or treating thromboembolic disorders.

\section{Conflict of Interests}

The authors declare that they have no conflict of interests.

\section{Authors' Contribution}

Dr. Wan-Jung Lu and Dr. Shih-Chang Lin contributed equally to this work.

\section{Acknowledgments}

This work was supported by grants from the National Science Council, Taiwan (NSC100-2320-B-038-021-MY3, NSC1022811-B-038-026, and MOST103-2811-B-038-023), and Cathay General Hospital-Taipei Medical University (103CGH-TMU01-2).

\section{References}

[1] Y. C. Hseu, W. C. Chang, Y. T. Hseu et al., "Protection of oxidative damage by aqueous extract from Antrodia camphorata mycelia in normal human erythrocytes," Life Sciences, vol. 71, no. 4, pp. 469-482, 2002.

[2] H. L. Yang, K. J. S. Kumar, and Y. C. Hseu, "Multiple molecular targets of Antrodia camphorata: a suitable candidate for ovarian cancer chemoprevention," in Breast Cancer Cells-2, Intech Press, Rijeka, Croatia, 2012.

[3] Y.-C. Chen, H.-L. Chiu, C.-Y. Chao et al., "New antiinflammatory aromatic components from Antrodia camphorata," International Journal of Molecular Sciences, vol. 14, no. 3, pp. 4629-4639, 2013.

[4] Y. U.-H. Hsieh, F.-H. Chu, Y. A.-S. Wang et al., "Antrocamphin A, an anti-inflammatory principal from the fruiting body of Taiwanofungus camphoratus, and its mechanisms," Journal of Agricultural and Food Chemistry, vol. 58, no. 5, pp. 3153-3158, 2010.

[5] H. L. Yang, K. Y. Lin, Y. C. Juan, and et al, "The anti-cancer activity of Antrodia camphorata against human ovarian carcinoma (SKOV-3) cells via modulation of HER-2/neu signaling pathway," Journal of Ethnopharmacology, vol. 148, no. 1, pp. 254265, 2013.
[6] C. C. Liaw, Y. C. Chen, G. J. Huang, and et al, "Antiinflammatory lanostanoids and lactone derivatives from Antrodia camphorata," Journal of Natural Products, vol. 76, no. 4, pp. 489-494, 2013.

[7] G. J. Huang, S. S. Huang, S. S. Lin, and et al, "Analgesic effects and the mechanisms of anti-inflammation of ergostatrien- $3 \beta$ ol from Antrodia camphorata submerged whole broth in mice," Journal of Agricultural and Food Chemistry, vol. 58, no. 12, pp. 7445-7452, 2010.

[8] J.-S. Deng, S.-S. Huang, T.-H. Lin et al., "Analgesic and antiinflammatory bioactivities of eburicoic acid and dehydroeburicoic acid isolated from antrodia camphorata on the inflammatory mediator expression in mice," Journal of Agricultural and Food Chemistry, vol. 61, no. 21, pp. 5064-5071, 2013.

[9] G.-J. Huang, J.-S. Deng, S.-S. Huang et al., "Hepatoprotective effects of eburicoic acid and dehydroeburicoic acid from Antrodia camphorata in a mouse model of acute hepatic injury," Food Chemistry, vol. 141, no. 3, pp. 3020-3027, 2013.

[10] J. R. Sheu, C. R. Lee, C. H. Lin, and et al, "Mechanisms involved in the antiplatelet activity of Staphylococcus aureus lipoteichoic acid in human platelets," Thrombosis and Haemostasis, vol. 83, no. 5, pp. 777-784, 2000.

[11] P. von Hundelshausen and C. Weber, "Platelets as immune cells: bridging inflammation and cardiovascular disease," Circulation Research, vol. 100, no. 1, pp. 27-40, 2007.

[12] J.-R. Sheu, W.-C. Hung, C.-H. Wu et al., "Reduction in lipopolysaccharide-induced thrombocytopenia by triflavin in a rat model of septicemia," Circulation, vol. 99, no. 23, pp. 30563062, 1999.

[13] W. D. Singer, H. A. Brown, and P. C. Sternweis, "Regulation of eukaryotic phosphatidylinositol-specific phospholipase C and phospholipase D," Annual Review of Biochemistry, vol. 66, pp. 475-509, 1997.

[14] Y.-C. Hseu, H.-L. Yang, Y.-C. Lai, J.-G. Lin, G.-W. Chen, and Y.-H. Chang, "Induction of apoptosis by Antrodia camphorata in human premyelocytic leukemia HL-60 cells," Nutrition and Cancer, vol. 48, no. 2, pp. 189-197, 2004.

[15] G. Hsiao, M.-Y. Shen, K.-H. Lin et al., "Antioxidative and hepatoprotective effects of Antrodia camphorata extract," Journal of Agricultural and Food Chemistry, vol. 51, no. 11, pp. 3302-3308, 2003.

[16] T.-Y. Song and G.-C. Yen, "Protective effects of fermented filtrate from Antrodia camphorata in submerged culture against CCl4-induced hepatic toxicity in rats," Journal of Agricultural and Food Chemistry, vol. 51, no. 6, pp. 1571-1577, 2003.

[17] P. Mangin, Y. Yuan, I. Goncalves et al., "Signaling role for phospholipase $\mathrm{C} \gamma 2$ in platelet glycoprotein $\mathrm{Ib} \alpha$ calcium flux and cytoskeletal reorganization: Involvement of a pathway distinct from FcR $\gamma$ chain and Fc $\gamma$ RIIA," Journal of Biological Chemistry, vol. 278, no. 35, pp. 32880-32891, 2003.

[18] A. Pascale, M. Amadio, S. Govoni, and F. Battaini, "The aging brain, a key target for the future: the protein kinase $\mathrm{C}$ involvement," Pharmacological Research, vol. 55, no. 6, pp. 560569, 2007.

[19] A. Ragab, S. Séverin, M.-P. Gratacap et al., "Roles of the Cterminal tyrosine residues of LAT in GPVI-induced platelet activation: insights into the mechanism of PLC $\gamma 2$ activation," Blood, vol. 110, no. 7, pp. 2466-2474, 2007.

[20] F. Bugaud, F. Nadal-Wollbold, S. Lévy-Toledano, J.-P. Rosa, and M. Bryckaert, "Regulation of c-Jun-NH2 terminal kinase and extracellular-signal regulated kinase in human platelets," Blood, vol. 94, no. 11, pp. 3800-3805, 1999. 
[21] F. Adam, A. Kauskot, J.-P. Rosa, and M. Bryckaert, "Mitogenactivated protein kinases in hemostasis and thrombosis," Journal of Thrombosis and Haemostasis, vol. 6, no. 12, pp. 2007-2016, 2008.

[22] P. Flevaris, Z. Li, G. Zhang, Y. Zheng, J. Liu, and X. Du, "Two distinct roles of mitogen-activated protein kinases in platelets and a novel Racl-MAPK-dependent integrin outsidein retractile signaling pathway," Blood, vol. 113, no. 4, pp. 893901, 2009.

[23] L. Coulon, C. Calzada, P. Moulin, E. Véricel, and M. Lagarde, "Activation of p38 mitogen-activated protein kinase/cytosolic phospholipase $\mathrm{A}_{2}$ cascade in hydroperoxide-stressed platelets," Free Radical Biology and Medicine, vol. 35, no. 6, pp. 616-625, 2003.

[24] A. Kauskot, F. Adam, A. Mazharian et al., "Involvement of the mitogen-activated protein kinase c-Jun $\mathrm{NH}_{2}$-terminal kinase 1 in thrombus formation," The Journal of Biological Chemistry, vol. 282, no. 44, pp. 31990-31999, 2007.

[25] F. Adam, A. Kauskot, P. Nurden et al., "Platelet JNK1 is involved in secretion and thrombus formation," Blood, vol. 115, no. 20, pp. 4083-4092, 2010.

[26] T. F. Franke, S.-I. Yang, T. O. Chan et al., "The protein kinase encoded by the Akt proto-oncogene is a target of the PDGFactivated phosphatidylinositol 3-kinase," Cell, vol. 81, no. 5, pp. 727-736, 1995.

[27] D. Woulfe, H. Jiang, A. Morgans, R. Monks, M. Birnbaum, and L. F. Brass, "Defects in secretion, aggregation, and thrombus formation in platelets from mice lacking Akt2," The Journal of Clinical Investigation, vol. 113, no. 3, pp. 441-450, 2004.

[28] J. Chen, S. De, D. S. Damron, W. S. Chen, N. Hay, and T. V. Byzova, "Impaired platelet responses to thrombin and collagen in AKT-1-deficient mice," Blood, vol. 104, no. 6, pp. 1703-1710, 2004. 

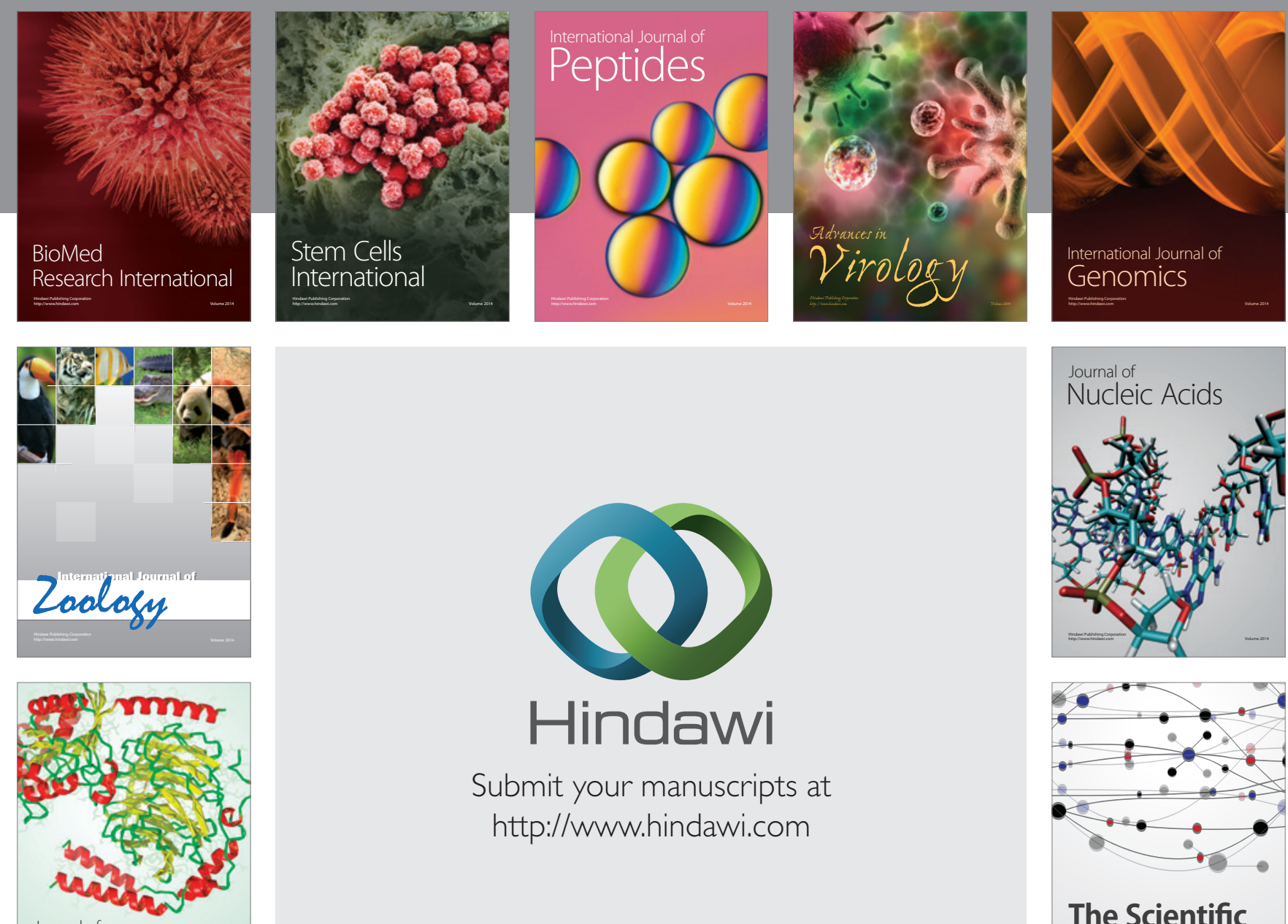

Submit your manuscripts at

http://www.hindawi.com

Journal of
Signal Transduction
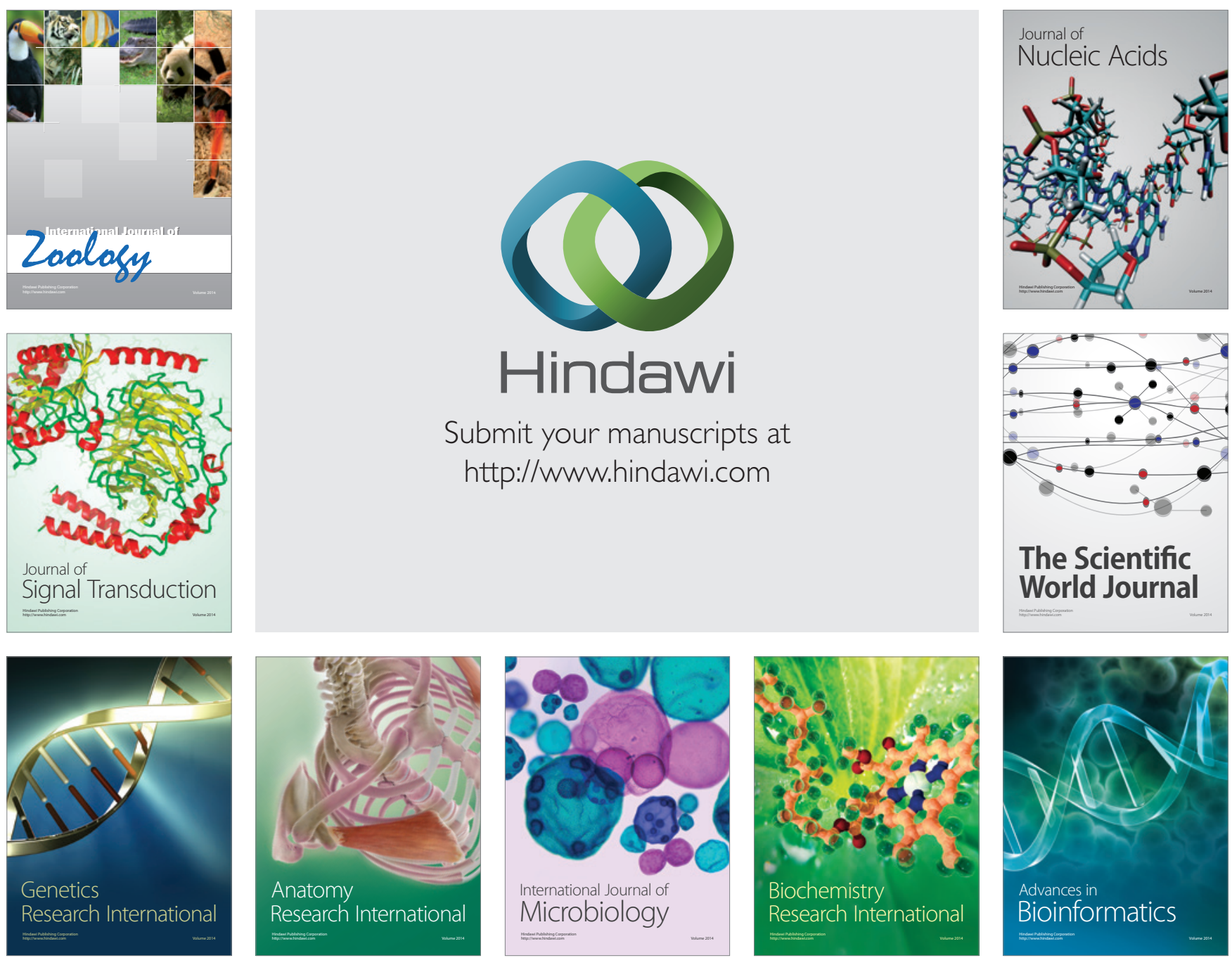

The Scientific World Journal
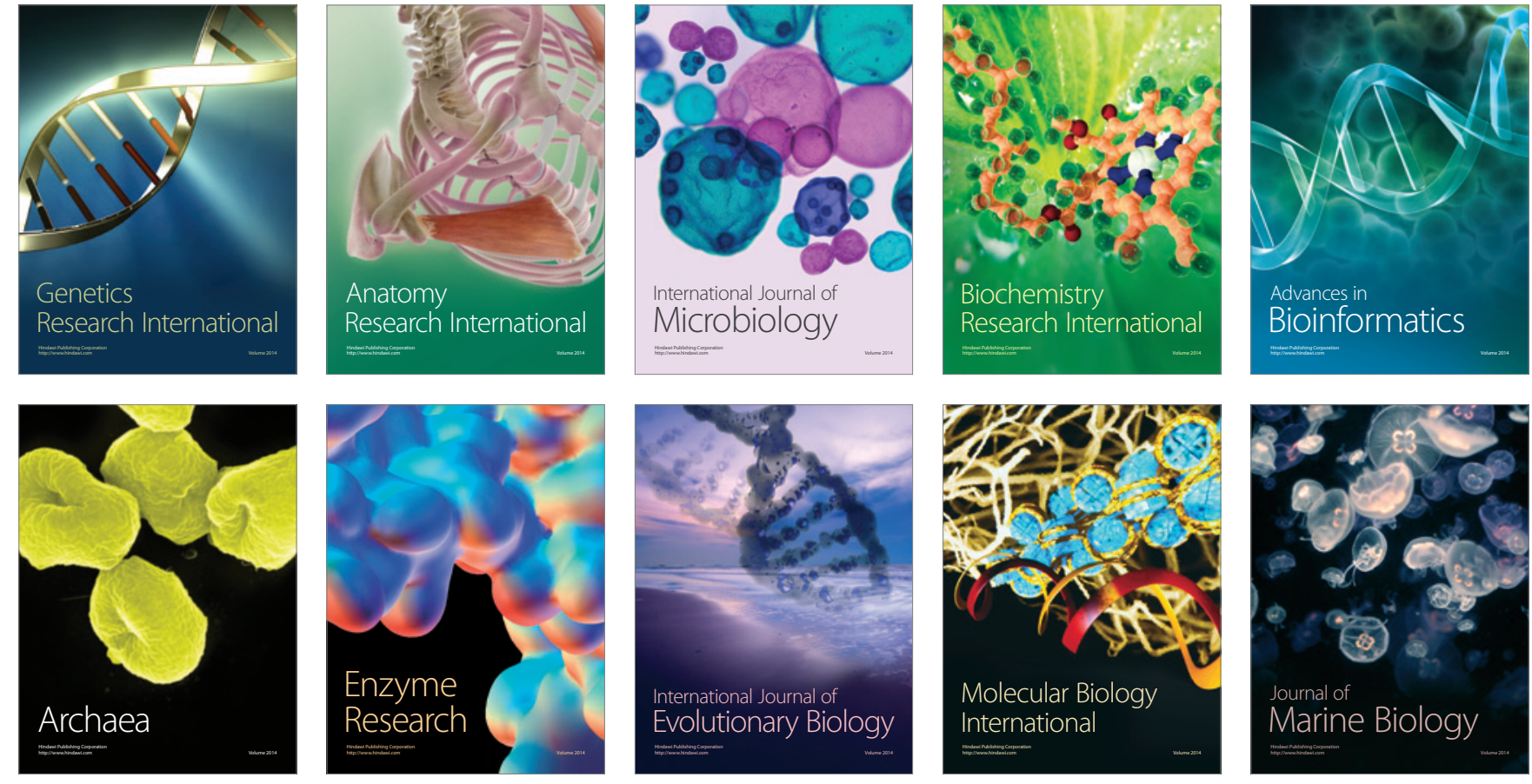